\title{
Surface Treatment to Provide a Metallic Luster to AZ31 Magnesium Alloy
}

\author{
Miyoshi Ohara $^{1}$ and Kenji Higashi ${ }^{2}$ \\ ${ }^{1}$ Kasatani $R \&$ \& Laboratory, Kasatani Corp., Osaka 532-0036, Japan \\ ${ }^{2}$ Department of Materials Science, Graduate School of Engineering, Osaka Prefecture University, Sakai 599-8531, Japan
}

To form a metallic luster on AZ31 magnesium alloy, it is necessary to optimize the surface morphology since the surface roughness affects the specular reflection of visible light, and the surface structure such as the film thickness and properties must be optimized so that light is not absorbed. We conducted experiments to analyze the relationship between surface roughness and specular reflection, and determined the range required to produce metallic luster. The ratio of the root mean square roughness $\sigma$ to the wavelength of incident light $\lambda$ was $0-0.067$, and the ratio of the specular reflectivity $R$ of the specimens to the specular reflectivity of a smooth surface $R_{0}$ was $0.54-1.0$. The thickness of film to form a metallic luster was theoretically analyzed and found to be about $100 \mathrm{~nm}$ or less. The authors developed an optimum acid aqueous solution for treating the surface to form a metallic luster on the surface of AZ31 magnesium alloy. This treatment satisfied the range required to form a metallic luster identified theoretically, and formed a film with a stable structure that maintained its metallic luster. The treatment maintained the geometrical patterns such as the hair-line and blast finishing of several hundred nm or more. A sufficiently high-quality surface for exterior parts was obtained by improving the process, and the process was industrialized. [doi:10.2320/matertrans.MC201010]

(Received December 3, 2010; Accepted March 28, 2011; Published May 25, 2011)

Keywords: magnesium alloy, metallic luster, surface treatment, acid aqueous solution treatment, surface roughness, specular reflectance, visual light range, specular glossiness, gloss, press forming

\section{Introduction}

Colorless and transparent methods of treating the surfaces of magnesium alloys have been reported. ${ }^{1)}$ However, the colorless and transparent methods of treating were applied only to the logo or front of the parts. The other parts were usually painted. In this surface treatment process, machining is usually used to create a metallic luster, but the metallic luster cannot be increased by further machining and so the design range is limited.

Metallic luster depends on the intensity of specular reflection from the metal. Specular reflection means that the angle of reflection is the same as the angle of incidence. To increase surface specular reflection, the surface morphology must be optimized since the surface roughness affects the specular reflection of visible light. A film of suitable thickness and properties such that light is not absorbed must be created. The surface structure, such as the film thickness and properties, must be optimized.

We optimized the surface morphology and structure by developing an acid aqueous solution for surface treatment to form a metallic luster on the surface of AZ31 magnesium alloy. $^{2-9)}$ We applied this treatment to a chassis, and formed a metallic luster on the entire chassis whole surface. To expand the design range of exterior parts, we maintained geometric patterns such as the hair line and blast finishing, etc. We also industrialized the optimum acid aqueous solution treatment, which we call the Mgbright ${ }^{\mathrm{TM}}$ process. $^{2,5)}$ Figure 1 shows photographs of components of a notebook computer to which Mgbright $^{\mathrm{TM}}$ was applied. ${ }^{10)}$

\section{Metallic Luster and Surface Roughness}

The surface morphology of a metal has irregularities of different order. In the present study, we considered two kinds of such surface morphology, one involving metallic luster, and the other involving geometric patterns that can be

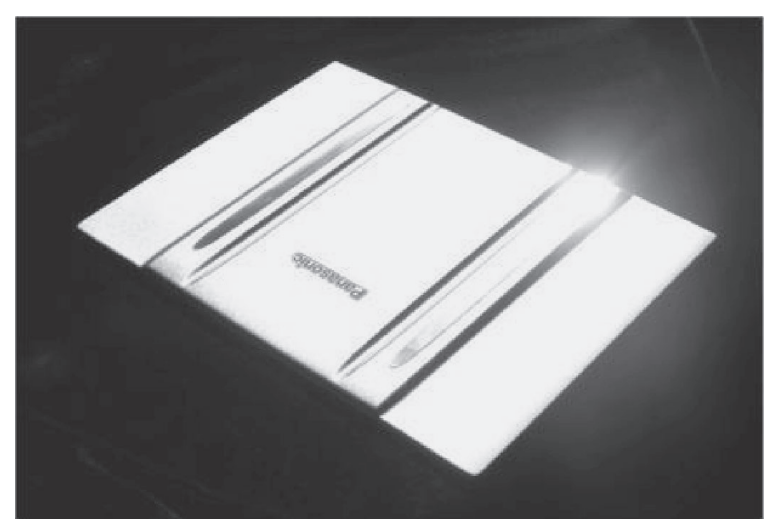

Fig. 1 Photograph of notebook computer part subjected to Mgbright ${ }^{\mathrm{TM}}{ }^{10)}$

visually seen as irregularities on the surface. Irregularities are usually quantified as surface roughness. It has been reported that the surface morphology involved in metallic luster is roughness smaller than the wavelength of visible light, of about $10-100 \mathrm{~nm} .^{11,12)}$ The roughness that can be visually confirmed such as a geometric pattern is considered to be several $1000 \mathrm{~nm}$.

A change in the surface roughness due to surface treatment can be distinguished by the order of surface roughness ${ }^{11-13)}$ (Fig. 2). Quantification of surface roughness of different order can be controlled by the cut-off when measuring the surface roughness. We assumed that the surface morphology involved in metallic luster is the root mean square roughness with a cut-off value of $0.002 \mathrm{~mm}$, and that the surface morphology involved in geometric patterns is the arithmetical mean roughness with a cut-off value of $0.8 \mathrm{~mm} .{ }^{8)}$

First, the surface roughness involved in metallic luster was analyzed. Metallic luster means that the specular reflection intensity is strong. A gloss-meter is used in industry to measure specular reflection intensity, which is called specular glossiness, $G_{\mathrm{s}}$. The specular glossiness $G_{\mathrm{s}}$ is the ratio 


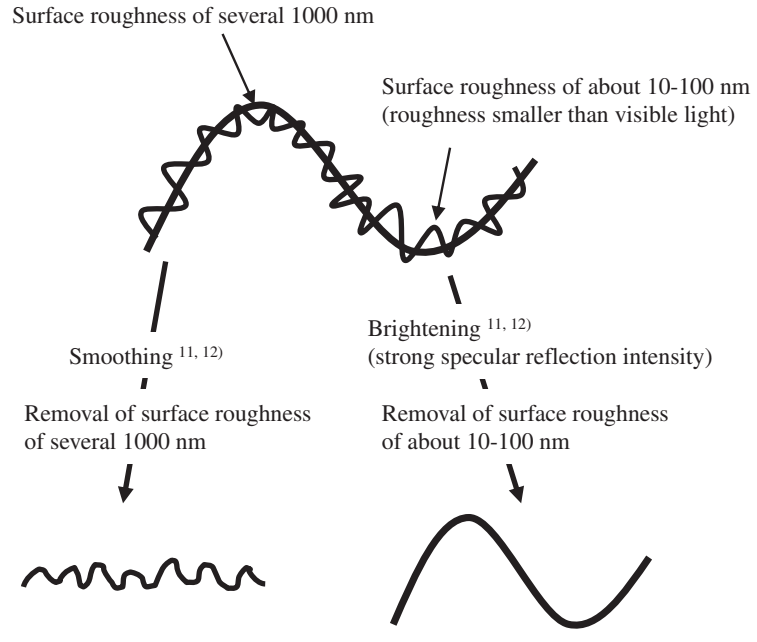

Fig. 2 Correlation of surface morphology (surface roughness) and smoothing and brightening. ${ }^{13)}$

of specular reflection intensity of the sample to that of a standard board. We quantified the specular reflection as a specular glossiness. The measurement angle of incidence, $\psi$, was $20^{\circ}$. The width of the measurement angle of the receiving light device of this gloss-meter $\Delta \theta$ was angle of incidence $\left.\pm 0.1^{\circ} .{ }^{9}\right)$

Davis reported the relation between specular reflection and scattered reflection and the surface roughness. ${ }^{14)} \mathrm{We}$ derived the following theoretical equation for the surface of AZ31 magnesium alloy by applying Davis's theory and the measurement conditions $\psi=20^{\circ}, \Delta \theta=0.2^{\circ}$ for the specular glossiness:

$$
\begin{aligned}
R / R_{0}= & \exp \left[-1.4 \times 10^{2}(\sigma / \lambda)^{2}\right] \\
& -2.8 \times 10^{-1}(\sigma / \lambda)^{4}\left(1 / \mathrm{m}^{2}\right) \\
& \times \exp \left[-8.2 \times 10^{-3}(\sigma / \lambda)^{2}\left(1 / \mathrm{m}^{2}\right)\right]
\end{aligned}
$$

where, $R$ is the specular reflectivity of the measurement surface of the specimen, $R_{0}$ is the specular reflectivity of a perfectly smooth surface, $\sigma$ is the root mean square roughness, $\lambda$ is the wavelength of incident light, and $m$ is the root mean square slope. ${ }^{9)}$ Expression (1) assumes that $\sigma \ll \lambda$. As mentioned above, the measured values contain both specular reflection as well as the scattered reflection to the angular width of the measurement of the optical receiver. The first term of eq. (1) is the specular reflection, while the second term is the scattered reflection to the angular width of the measurement of the optical receiver.

We analyzed the specular glossiness, $G_{\mathrm{s}}\left(20^{\circ}\right)$, and the root mean square roughness, $\sigma$, of the sample processed by the acid aqueous solution treatment by eq. (1), ${ }^{9)}$ and found that the experiment results closely matched those obtained by the equation. Figure 3 shows the relation between $R / R_{0}$ and $\sigma / \lambda$ for an angle of incidence of $20^{\circ}$.

Next, the range of surface roughness for obtaining metallic luster was calculated. Aoki reported that the condition for specular reflection is given by: ${ }^{15)}$

$$
h / \lambda<1 /\{8 \sin [(\pi / 2)-\psi]\}
$$

where, $h$ is the height of irregularities on the reflecting surface, $\psi$ is the angle of incidence, and $\lambda$ is the wavelength of incident light. The range of surface roughness for

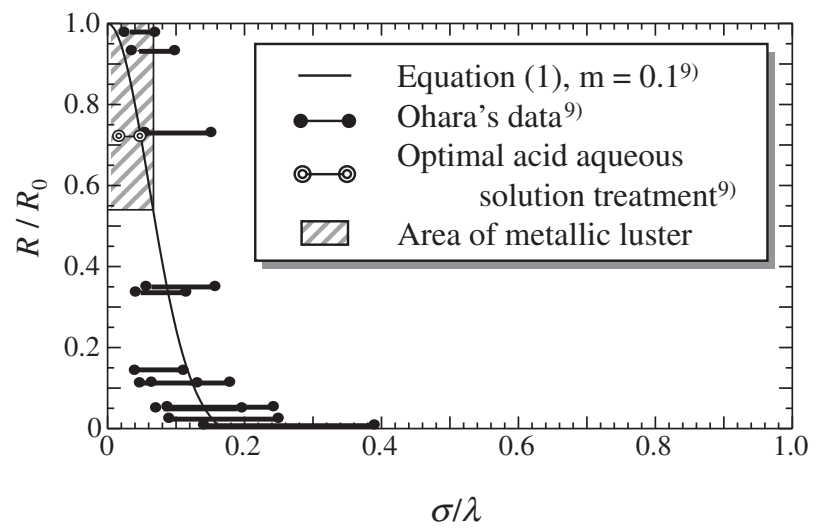

Fig. 3 Relationship between $R / R_{0}$ and $\sigma / \lambda$ at angle of incidence of $20^{\circ}$.

producing metallic luster was calculated by eq. (2). The equation for calculating the root mean square roughness $\sigma$ is: ${ }^{8)}$

$$
\sigma=\sqrt{(1 / l) \int_{0}^{l} Z^{2}(x) d x}
$$

$Z$ is the height from the mean line. By replacing $Z$ in eq. (3) with $h / 2$ and calculating, $h$ is obtained as $2 \sigma$. Substituting $h=2 \sigma$ in eq. (2) gives:

$$
\sigma / \lambda<1 /\{16 \sin [(\pi / 2)-\psi]\}
$$

This equation shows the range of surface roughness for obtaining metallic luster, and for an angle of incidence of $20^{\circ}$, gives the range $0<\sigma / \lambda<0.067$. Moreover, the range of the ratio of specular reflection, $R / R_{0}$, at which metallic luster was produced is calculated by using $0<\sigma / \lambda<0.067$ and eq. (1), yielding $0.54<R / R_{0}<1$. Figure 3 shows the range where metallic luster is produced.

Next, we examined optimization of the surface treatment liquid element and the surface treatment conditions by acid aqueous solution treatment. ${ }^{3,6,7)}$ It was clarified that the optimum surface treatment liquid with the supersonic wave frequency of $28 \mathrm{kHz}$ for $30 \mathrm{~s}$ was $0.3-0.5 \mathrm{~mol} \mathrm{dm}^{-3}$ nitric acid with $0.01 \mathrm{~mol} \mathrm{dm}^{-3}$ organic acid, and the optimum temperature was $278 \mathrm{~K}$. We decided to perform optimum acid aqueous solution treatment under these conditions. ${ }^{7)}$ The ratio $\sigma / \lambda$, with $\lambda=500 \mathrm{~nm}$, of the optimum acid aqueous solution treatment was 0.029 , and $R / R_{0}$ was $0.72 .^{9)}$ This result shows the range where metallic luster is produced, and is shown in Fig. 3. We confirmed that surface treatment using the optimum acid aqueous solution formed a metallic luster.

It is necessary to maintain the geometric pattern to expand the range of design selection. The roughness that can be visually confirmed as a geometric pattern is considered to be several $1000 \mathrm{~nm}$. The change in the geometric pattern by the optimum acid aqueous solution treatment was confirmed by the normalized gloss, $G_{\mathrm{S}_{\mathrm{N}}}$, and the arithmetical mean roughness, $R_{\mathrm{a}}{ }^{4)}$ Figure 4 shows the result. ${ }^{4,5,13)}$ The normalized gloss is the ratio of the specular glossiness of a specimen to the specular glossiness of a specimen polished by \#2000 emery paper. The surface was polished by several mechanical methods. The arithmetic mean roughness $R_{\mathrm{a}}$ hardly changed and the normalized gloss $G_{\mathrm{S}_{\mathrm{N}}}$ increased. This result showed 


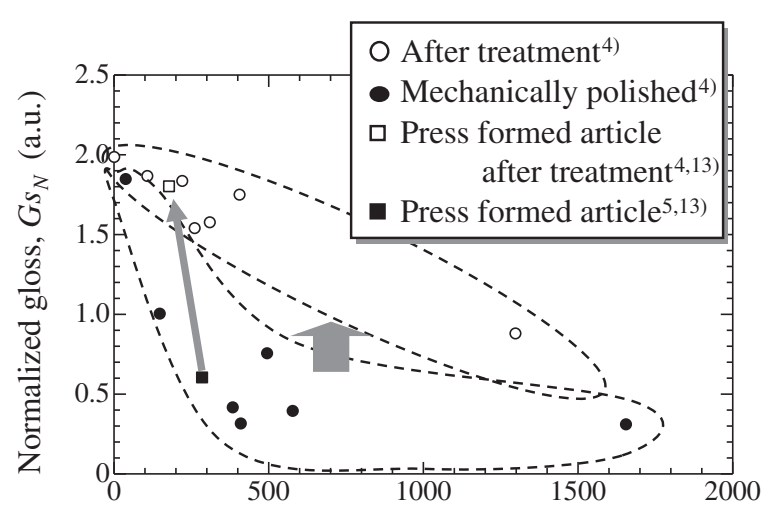

Arithmetical mean roughness, $R a / \mathrm{nm}$

Fig. 4 Relationship between arithmetical mean roughness with a cut-off value of $0.8 \mathrm{~mm}$ and normalized gloss. ${ }^{13)}$

that the optimum acid aqueous solution treatment maintained roughness of several $1000 \mathrm{~nm}$, which is the surface roughness of the geometric pattern. In addition, it was confirmed that a geometric pattern with surface roughness of several hundred $\mathrm{nm}$ could be maintained.

As described above, the developed optimum acid aqueous solution is a surface treatment that forms a metallic luster while maintaining the geometric pattern.

\section{Metallic Luster and Surface Structure}

\subsection{Film thickness}

To form a metallic luster, it is necessary to control the film thickness, which we decided should be in the range of about $100 \mathrm{~nm}$ or less, as shown below.

Figure 5 shows pattern diagrams of the reflection of light and penetration when a transparent, smooth thin film exists on the metal. The total reflected light from the surface is the sum of the reflected light from points A1, A2 and other points. However, interference is caused by the reflected light at various locations. This interference depends on the angle of incidence, wavelength of light, and film thickness. If the angle of incidence is constant, the film thickness required to maximize the brightness of the reflected light is given by: $\left.{ }^{15}\right)$

$$
d=(2 i-1) \lambda / 4 n_{2}(i=1,2,3, \ldots)
$$

where, $d$ is the film thickness, $\lambda$ is the wavelength of incident light, and $n_{2}$ is the refractive index of the film. If a magnesium oxide film is formed, the film thickness ( $i=1-7)$ at which the brightness becomes the maximum is a wavelength within the visible light range, as shown in Table 1. The refractive index of the magnesium oxide was 1.74. ${ }^{16)}$ At the film thickness at which the brightness of reflected light is maximum, the human eye perceives color in the film, and this color depends on the wavelength. The color can be changed by the combination of the wavelength, when the brightness of reflected light at several different wavelengths was the maximum at the same film thickness. For example, the brightness of the reflected light of wavelength of about 380,485 , and $700 \mathrm{~nm}$ becomes the maximum for the film thickness of about $500 \mathrm{~nm}$ as shown in Table 1. Thus, the human eye perceives the color of the combination of the wavelength of about 380, 485 and $700 \mathrm{~nm}$ for the

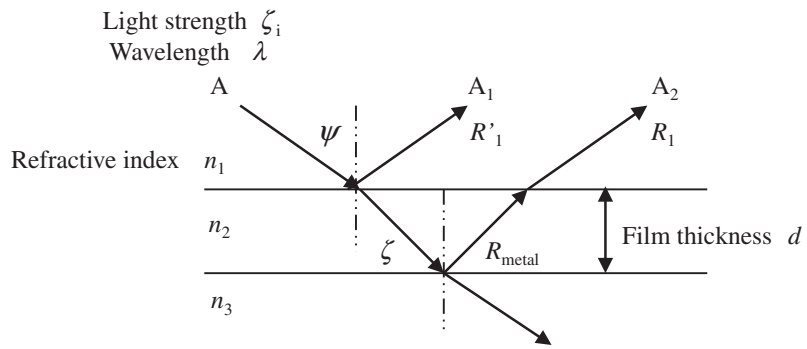

Fig. 5 Pattern diagrams of reflection of light and penetration when a transparent, smooth thin film exists on metal.

Table 1 Film thickness $(i=1-7)$ for maximum brightness at wavelengths within the range of visible light.

\begin{tabular}{|c|c|c|c|c|c|c|c|c|}
\hline \multirow[t]{2}{*}{$\begin{array}{c}\text { Wavelength, } \\
\lambda / \mathrm{nm}\end{array}$} & \multicolumn{8}{|c|}{$\begin{array}{l}\text { Film thickness, } \\
\qquad d / \mathrm{nm}\end{array}$} \\
\hline & $i$ & 1 & 2 & 3 & 4 & 5 & 6 & 7 \\
\hline 380 & & 55 & 164 & 273 & 382 & 491 & 601 & 710 \\
\hline 485 & & 70 & 209 & 348 & 488 & 627 & 767 & 906 \\
\hline 530 & & 76 & 228 & 381 & 533 & 685 & 838 & 990 \\
\hline 575 & & 83 & 248 & 413 & 578 & 744 & 909 & 1074 \\
\hline 620 & & 89 & 267 & 445 & 624 & 802 & 980 & 1158 \\
\hline 770 & & 111 & 332 & 553 & 774 & 996 & 1217 & 1438 \\
\hline
\end{tabular}

film thickness of about $500 \mathrm{~nm}$. When the film thickness is such that the brightness of the reflected light becomes the maximum over the whole range of visible light wavelength, light interference can be disregarded because the reflected light becomes white.

The strength of specular reflection decreases when the reflected light becomes white, and the film thickness becomes thick when light interference can be disregarded. According to Lambert's law, the intensity $\zeta$ is given by the following equation if the intensity of the light $\zeta_{i}$ advances the distance $z$ in the absorbing media: ${ }^{17)}$

$$
\zeta=\zeta_{i} \exp (-\alpha z)
$$

where, $\alpha$ is the absorbing coefficient of the absorbing media. The distance moved by light, $z$, is replaced with the film thickness. It can be understood that with greater film thickness, the intensity of light penetration decreases, and so the specular reflection intensity decreases, too. Thus, a thicker film hinders the realization of metallic luster.

Note that the condition for light interference includes the condition that the reflection of light decreases, as shown by the following equation: ${ }^{18}$

$$
d=(1 / 4)\left(\lambda / n_{2}\right)
$$

This equation shows the destructive interference. ${ }^{18)}$ The value of $i=1$ in Table 1 shows film thickness, $d$, on the destructive interference. The film thickness is calculated by eq. (7). This result showed that a colorless film can be formed when the thickness of the magnesium oxide film is about $100 \mathrm{~nm}$ or less.

Magnesium oxide, magnesium hydroxide, or other compounds are expected to form on the surface of magnesium alloy when soaked in the acid aqueous solution. The refractive index of magnesium hydroxide is $1.56 .{ }^{19)}$ In the hydroxide magnesium film that was formed, the condition of 


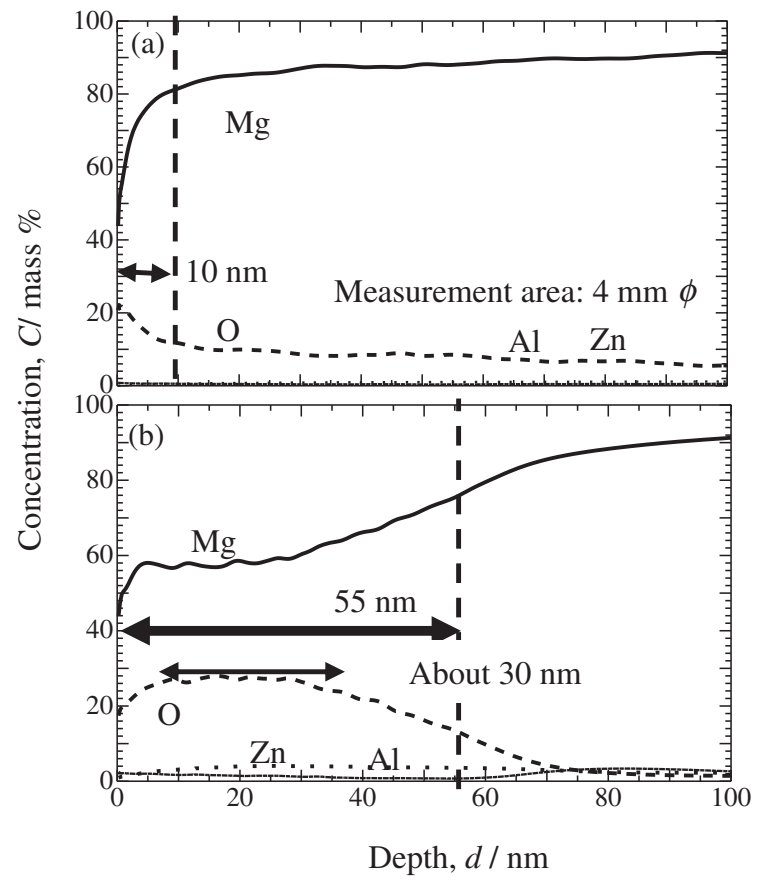

Fig. 6 Depth profiles of constituent elements of the specimen using glow discharge optical emission spectrometer: (a) surface polished by \#2000 emery paper and (b) surface after optimal acid aqueous solution treatment. ${ }^{7)}$

destructive interference was calculated by eq. (7) as well as the condition for formation of the magnesium oxide film. If $\lambda$ was $770 \mathrm{~nm}, d$ was $123 \mathrm{~nm}$, which is almost the same result as that for magnesium oxide. For these reasons, it was decided that the range of film thickness to form a metallic luster was about $100 \mathrm{~nm}$ or less.

Magnesium oxide formed on the surface of AZ31 magnesium alloy subjected to the optimum acid aqueous solution treatment. ${ }^{3,7)}$ Thus, a film thickness of about $100 \mathrm{~nm}$ or less is suitable for forming metallic luster. The depth profiles of constituent elements of the specimen using a glow discharge optical emission spectrometer (GD-OES) of (a) the surface polished by \#2000 emery paper and (b) the surface after the optimum acid aqueous solution treatment are shown in Fig. 6. ${ }^{7)}$ The oxide film thickness was set to half the width of an oxygen atom based on the result of GD-OES. ${ }^{7)}$ The oxide film thickness of the surface after the optimum acid aqueous solution treatment was $55 \mathrm{~nm} .{ }^{7)}$ The result clarified that the optimum acid aqueous solution achieved a film thickness of about $100 \mathrm{~nm}$ or less which is necessary to form a metallic luster.

Figure 7 shows the secondary electron and back reflected electron images in the section of the sample subjected to the optimum acid aqueous solution treatment. ${ }^{13}$ ) The oxide film on the surface could not be confirmed in the secondary electron image. Also, it was confirmed that a micron-order oxide film did not form at least in the back reflected electron image. However, it was possible to observe a very thin oxide film formed on the surface. In the secondary electron and back reflected electron images, the oxide film thickness of $55 \mathrm{~nm}$ as decided by GD-OED could not be confirmed and therefore detailed further observation is necessary on the oxide film thickness.

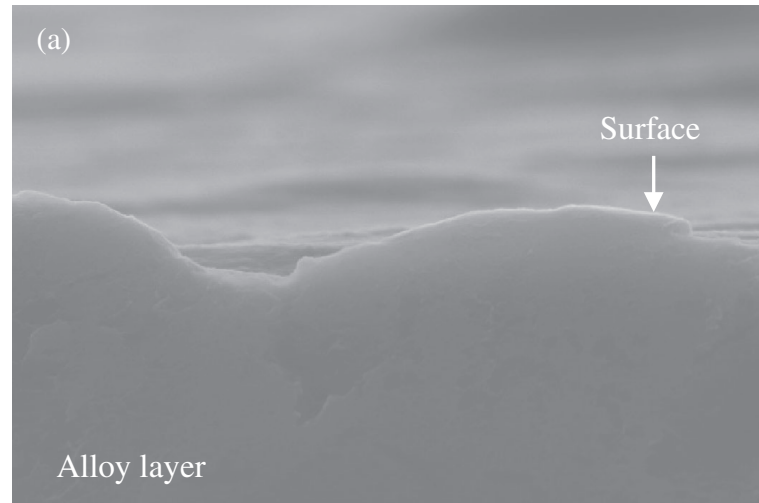

\section{(b)}

Alloy layer

Fig. 7 (a) Secondary electron and (b) back reflected electron images in section of sample subjected to optimal acid aqueous solution treatment. ${ }^{13)}$

\subsection{Corrosion resistance and properties of the film}

It is considered that a larger film thickness generally improves the corrosion resistance of magnesium alloys, and various surface treatment methods have been developed. ${ }^{20-24)}$ Figure 8 shows the thickness of the oxide film on the fresh surface of magnesium alloy and the dependency of the corrosion rate on the concentration of aluminum. ${ }^{26,31)}$ The film thickness decreases as the concentration of aluminum in the magnesium alloy increases, and the corrosion resistance is improved. It was reported that this result was due to stabilization of the film by the aluminum that concentrates in the oxide film. ${ }^{27,28)}$ It was also reported that the corrosion resistance is influenced by not only the film thickness and the precision of the film formed by the surface treatment, but also by the properties of the film, based on an examination of the relation between the structure and the corrosion resistance of the anode oxide film of magnesium alloys. ${ }^{29)}$ In view of these reports, it is important to control the properties of the film rather than thickness in order to improve the corrosion resistance.

The formation of magnesium oxide on the surface of magnesium is expected to stabilize the surface. The structure of a natural oxide of magnesium and magnesium alloys is reported to be as follows. The $\mathrm{Mg}_{2 \mathrm{p}}$ peak of the XPS spectrum for the initial film formed on pure magnesium was analyzed. The result showed that the $\mathrm{Mg}_{2 \mathrm{p}}$ peak of the initial film corresponded to elemental magnesium, magnesium oxide and magnesium hydrate. ${ }^{30)}$ The amount of magnesium hydrate in the film was estimated to range from 50 to 


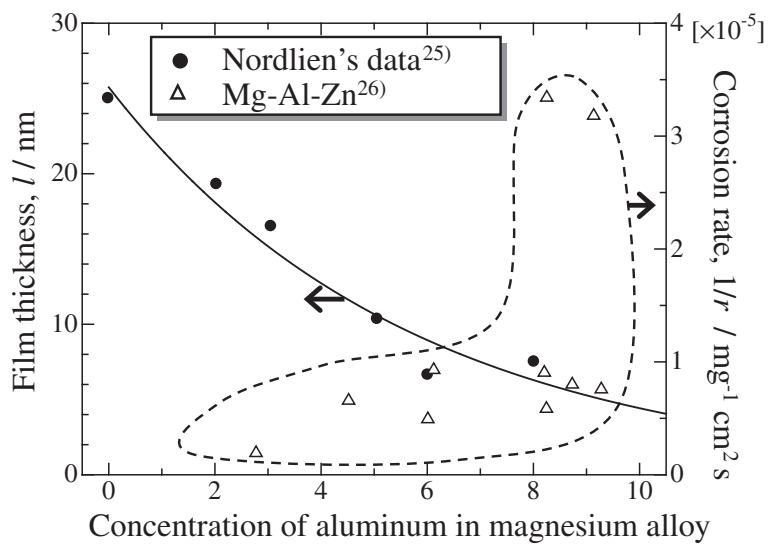

(mass\%)

Fig. 8 Thickness of oxide film on fresh surface of magnesium alloy and dependency of corrosion rate on the concentration of aluminum.

60 mass $\% .^{30)}$ In humid air, a hydrated layer was formed between the metal and initial film. In magnesium alloys, the hydrated layer was formed in humid air, too. ${ }^{25,30-33)}$ On the surface of magnesium and magnesium alloys, an initial film containing magnesium oxide was formed, but the structure of the surface changed in humid air. The authors reported a difference in the structure of the surface polished by \#2000 emery paper and the surface after optimum acid aqueous solution treatment in humid air. ${ }^{7)}$ A film containing magnesium oxide formed on the surface polished by \#2000 emery paper, and the structure changed in humid air. In the optimum acid aqueous solution treatment to form a metallic luster, magnesium oxide was formed on the surface by using nitric acid as the oxidant. The structure of the surface after this treatment did not change in humid air. ${ }^{7)}$ These results suggest that the contribution of magnesium oxide to corrosion resistance is related to not only the formation of magnesium oxide but also its amount.

Figure 9 shows the relation between the amount of oxidation magnesium per unit film thickness and luster stability. ${ }^{7)}$ The amount for the film on the specimen surface after acid aqueous solution treatment was more than that of a specimen polished by \#2000 emery paper, and the stability of the metallic luster was good. This result showed that the amount of oxidation magnesium in the film of magnesium alloy influenced the corrosion resistance. It is necessary to form a film with sufficiently stable structure on the surface to improve the corrosion resistance of magnesium alloys. The developed optimum acid aqueous solution treatment creates such a film with a stable structure that maintains the metallic luster.

\section{Application to Press-Forming}

For exterior parts such as the chassis which are the targets of this study, not only the size accuracy of the chassis but also high Kansei value, such as a good external appearance, is necessary. ${ }^{34)}$ Damage occurs during the press working of usual magnesium alloys, ${ }^{5)}$ and a high-quality press-forming process that suppresses such damage has been industrially developed. ${ }^{5,35-39)}$ We investigated the possibility of applying the optimum acid aqueous solution treatment to industrial

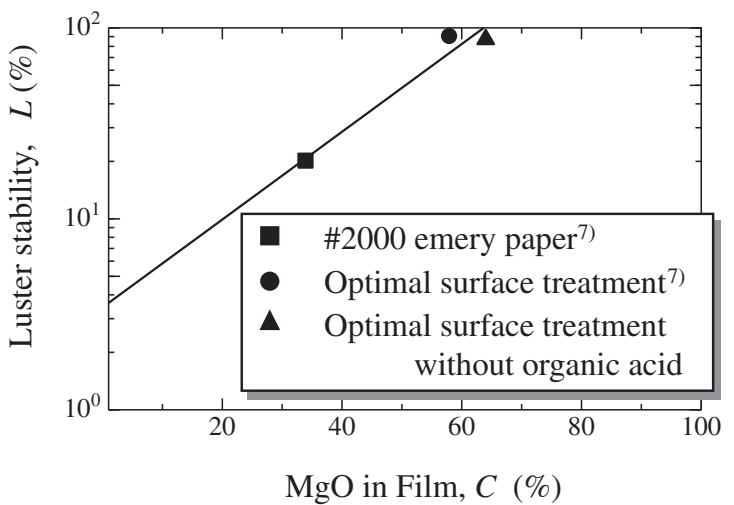

Fig. 9 Relationship between $\mathrm{MgO}$ in film and luster stability on AZ31 magnesium alloy. Luster stability, $L$, was quantified by ratio of specular gloss, $G_{\mathrm{s}}\left(60^{\circ}\right)$, before and after environment test. Temperature, humidity and time of environment test were in $333 \mathrm{~K}, 95 \%$ and $604.8 \mathrm{ks}$, respectively.

Table 2 Conditions for forming metallic luster and for optimal acid aqueous solution treatment.

\begin{tabular}{|c|c|c|}
\hline & $\begin{array}{l}\text { Conditions } \\
\text { for forming metallic luster }\end{array}$ & $\begin{array}{l}\text { Conditions for optimal acid } \\
\text { aqueous solution treatment }\end{array}$ \\
\hline $\begin{array}{c}\text { Surface } \\
\text { morphology }\end{array}$ & $\begin{array}{c}0<\sigma / \lambda<0.067 \\
\text { (cut-off }=0.002 \mathrm{~mm})\end{array}$ & $\begin{array}{l}\sigma / \lambda=0.029 \\
(\lambda=500 \mathrm{~nm})\end{array}$ \\
\hline \multirow{2}{*}{$\begin{array}{l}\text { Surface } \\
\text { structure }\end{array}$} & Film thickness $<$ about $100 \mathrm{~nm}$ & Film thickness $=55 \mathrm{~nm}$ \\
\hline & $\begin{array}{l}\text { Forming property of film } \\
\text { of stable structure }\end{array}$ & $\begin{array}{l}\text { Oxidation magnesium } \\
\text { in the film } \geqq 60 \%\end{array}$ \\
\hline $\begin{array}{l}\text { Specular } \\
\text { reflectivity }\end{array}$ & $0.54<R / R_{0}<1.0$ & $R / R_{0}=0.72$ \\
\hline
\end{tabular}

processes for high-quality press forming. As a result, the normalized gloss was improved with almost no change in the arithmetic mean roughness as shown in Fig. 4. It was thus confirmed that the optimum acid aqueous solution treatment was suitable not only for the standard specimen whose surface was polished by a machine, but also for press-forming products. ${ }^{4,5,13)}$

Exterior parts such as the chassis of notebook computers require durability, chemical resistance, abrasion resistance, etc., as well as metallic luster and luster stability. Therefore, a clear coating process for use after the optimum acid aqueous solution treatment was developed. ${ }^{5)}$ This surface treatment process is called Mgbright $^{\mathrm{TM}}$, which achieves the surface performance required of exterior parts.

\section{Summary}

In developing a surface treatment to form a metallic luster on the surface of AZ31 magnesium alloy, we set a target value by clarifying the surface morphology and structure required to form a metallic luster, and optimized the surface treatment method accordingly. The conditions required to form a metallic luster were clarified, and the conditions of the optimum acid aqueous solution treatment are shown in Table 2. We found that the optimum acid aqueous solution treatment maintained geometrical patterns, such as hair-line and blast, of several hundred nm or more. In addition, the surface performance required for exterior parts was obtained by improving the process suitable for industrial use. 
There have been few studies on the surface of magnesium alloys and much remains unknown. We hope the results of this study will be useful for further research in the future.

\section{REFERENCES}

1) Handbook of Advanced Magnesium Technology, (Kallos Publishing, Tokyo, 2000).

2) H. Okahara: Arutopia 2003-2 (2003) 21-26.

3) M. Ohara, H. Okahara and K. Higashi: J. Surface Finish. Soc. Japan 56 (2005) 698-699.

4) M. Ohara, H. Okahara, Y. Takigawa and K. Higashi: Mater. Trans. 49 (2008) 909-912.

5) M. Ohara, Y. Takigawa and K. Higashi: Mater. Sci. Forum 610-613 (2009) 999-1002.

6) M. Ohara, Y. Takigawa and K. Higashi: Proc. 138th TMS Annual Meeting \& Exhibition, Magnesium Technology 2009, (2009) pp. 343 345.

7) M. Ohara, Y. Takigawa and K. Higashi: J. JILM 60 (2010) 117-123.

8) M. Ohara, Y. Takigawa and K. Higashi: J. JILM 60 (2010) 259-263.

9) M. Ohara, Y. Takigawa and K. Higashi: J. Japan Inst. Metals 74 (2010) 788-793.

10) Photo credit (Panasonic Corporation).

11) T. Saji: J. Metal Finish. Soc. Japan 14 (1963) 129-134.

12) W. J. Mcg. Tegart: The Electrolytic and Chemical Polishing of Metals in Research and Industry (Pergamon Press, 1956).

13) M. Ohara: Academic Dissertation, (Osaka Prefecture University, 2009).

14) H. Davies: Proc. Inst. Electr. Eng. 101 (1954) 209-214.

15) S. Aoki: Introduction to Optics, (Kyoritsu Publishing Co., Ltd., Tokyo, 2002).

16) Encyclopaedia Chimica 3, (Kyoritsu Publishing Co., Ltd., Tokyo, 2006) p. 940.

17) M. Kobiyama: Kougakuhakumaku no Kisorironn (The Optronics Co., Ltd., Tokyo, 2003) p. 13.

18) K. Satoh, M. Ohashi, Y. Kishikawa and T. Araki: The Chemical Times 190 (2003) 7-9.
19) Encyclopaedia Chimica 5, (Kyoritsu Publishing Co., Ltd., Tokyo, 2006) p. 37.

20) M. Takaya: J. JILM 50 (2000) 567-576.

21) M. Hara, K. Matsuda, W. Yamauchi, M. Sakaguchi, T. Yoshikata, Y. Takigawa and K. Higashi: Mater. Trans. 47 (2006) 1013-1019.

22) M. Hara, K. Matsuda, W. Yamauchi, M. Sakaguchi, T. Yoshikata, Y. Takigawa and K. Higashi: Mater. Trans. 48 (2007) 3118-3125.

23) M. Hino, K. Murakami, A. Saijo and T. Kanadani: J. Surface Finish. Soc. Japan 58 (2007) 767-773.

24) Y. Zhang, C. Yan, F. Wang, H. Lou and C. Cao: Surface Coat. Technol. 161 (2002) 36-43.

25) J. H. Nordlien, K. Nisancioglu, S. Ono and N. Masuko: J. Electrochem. Soc. 143 (1996) 2564-2572.

26) O. Lunder, K. Nisancioglu and R. S. Hansen: SAE Technical Paper No. 930755 (1993) 117-126.

27) S. Ono: J. Surface Finish. Soc. Japan 53 (2002) 166-171.

28) K. Nisancioglu and O. Lunder: J. Surface Finish. Soc. Japan 44 (1993) 883-889.

29) M. Okido: J. JILM 60 (2010) 142-149.

30) J. H. Nordlien, S. Ono, N. Masuko and K. Nisancioglu: Corros. Sci. 39 (1997) 1397-1414.

31) J. H. Nordlien, S. Ono and N. Masuko: J. Electrochem. Soc. 142 (1995) 3320-3322.

32) J. H. Nordlien, K. Nisancioglu, S. Ono and N. Masuko: J. Electrochem. Soc. 144 (1997) 461-466.

33) K. Asami and S. Ono: J. Electrochem. Soc. 147 (2000) 1408-1413.

34) "Kansei" Initiative (Ministry of Economy, Trade and Industry, Japan, 2007).

35) E. Goto, T. Kachi, H. Okahara, Y. Takigawa and K. Higashi: Mater. Trans. 47 (2006) 1782-1787.

36) H. Okahara, M. Ohara, Y. Takigawa and K. Higashi: Mater. Trans. 47 (2006) 954-958

37) T. Kumagai, K. Shimamura, H. Okahara, Y. Takigawa and K. Higashi: Mater. Trans. 47 (2006) 1008-1012.

38) J. Sasaya, S. Nagumo, A. Nakayama, T. Kumagai, N. Shirakawa, H. Okahara and K. Higashi: Sokeizai 47-5 (2006) 20-25.

39) J. Sasaya, H. Okahara, M. Yano, M. Shirakawa and K. Higashi: Sokeizai 47-5 (2006) 30-34. 